\title{
Publika museirum
}

\section{Hur kulturpolitiska ideal materialiseras i offentliga rum på Historiska museet 1943-2013}

\author{
Britta ZetTerström Geschwind
}

Title: Public museum space. How cultural policies and democratic ideals materialize in the public spaces of the Swedish History Museum 1943-2013

\begin{abstract}
The research subject is the Swedish History Museum in Stockholm as a public institution between 1943 and 2013. I examine how public spaces in the museum body are designed in relation to cultural policy objectives and the museum's vision of a democratic, inclusive museum. However, the focus is not on the museum's exhibits, but on other public spaces visitors encounter in the museum, mainly the entrance, the shop and children's spaces. These spaces tend to be invisible in the museum hierarchy, and their practices are rarely observed in museum studies. Main research questions are: How are democratic ideals materialized and expressed over time? Which publics are created by the public spaces?
\end{abstract}

Keywords: Public museum space, cultural policy, materiality, Swedish History Museum, children, situated knowledge.

Detta är en presentation av mitt avhandlingsprojekt i etnologi och Forskarskolan för kulturhistoriska studier vid Stockholms universitet. Studieobjektet är Historiska museet i Stockholm vilket grundades som ett modernt museum 1866, då det var inrymt i bottenvåningen av Nationalmuseum. En ny museibyggnad på Narvavägen stod klar 1939. Fokus riktas mot tiden från öppnandet 1943 fram till 2013. Byggnaden, en kompromiss mellan avskalad funktionalism och en traditionell storslagen nationalism, präglas av sin tillkomsttid i folkhemsepok och krigskontext.

\section{DET PUBLIKA MUSEET}

Museernas demokratiska roller och ansvar har flitigt analyserats de senaste 30 åren. Museer har kallats mötesplatser, kontaktzoner, torg eller under senare år "tredje rummet". ${ }^{1}$ Men de har också kallats kunskapstempel, exkluderande, kontrollerande och övervakande, ofta i studier inspirerade av Michel Foucault. Det finns anledning att reflektera över museernas rumsliga metaforer mer konkret. Det statliga skattefinansierade museets status som en publik, demokratisk institution av och för folket legitimerar dess existens. Relevansen ligger i att de 
är tillgängliga. Men vad betyder det egentligen att museet är tillgängligt och publikt? Och vilka rum är det man talar om som publika? Hur har de publika rummen förändrats - eller varit sig lika - över tid? Begreppet publik har en dubbel innebörd och innefattar dels hur museet konkret är utformat för en publik, dels hur det är offentligt (public) i en demokratisk mening. Jag väljer att använda begreppet "publika" rum framför "offentliga" eftersom det rymmer både betydelsen publikt (som för besökande/åskådare) och offentligt (för en allmänhet).

I kärnan av museet som publik institution ligger några viktiga motsättningar som har lång kontinuitet, men som förskjutits över tid. De kan förenklat beskrivas som spänningar mellan vad Magdalena Hillström och Svante Beckman i en fyrfältsmodell betecknat "samlingsorientering" kontra "publikorientering" och "lärdomskultur" kontra "upplevelsekultur" (Hillström \& Beckman 2001, Hillström 2005:105). I relation till dessa identifieras fyra idealbilder av museet: "skattkammaren", "arkivet", "folkhögskolan" och "teatern". Dikotomier som dessa är bra att tänka med, men det finns en risk med att kronologisera idealtyper. Markeringen av "det nya" i museers fokus på deltagande, kommunikation och upplevelser, begrepp som nu är vanliga i museisfären, kan skapa en förenklad kontrastering mot det förflutna. Utan empiriska, kulturhistoriska jämförelser kan deltagarmetaforer användas normativt och oreflekterat och dölja maktaspekter mellan institution och individ idag. Mitt förhållningssätt har varit att i relation till Hillström och Beckmans idealtyper empiriskt undersöka spänningsförhållanden mellan framför allt kultur och kommers och mellan lärande och upplevelse. ${ }^{2}$ Här ingår spänningar mellan olika kunskaps- och verksamhetsområden inom museet, som mellan pedagogiska, arkeologiska och kommersiella syften. Jag tänker mig att det är genom översättningar och förhandlingar mellan olika spänningsfält som museets publika kropp formas.

\section{FORSKNINGSPROJEKTET}

I likhet med många andra museistudier är alltså museets demokratiska och publika roller i fokus. Jag utgår dock inte, som i många andra fall, från utställningarna utan från andra publika museirum. I synnerhet behandlas entré, butik, barnrum och museets innergård/utomhusrum (fig. 1). Utställningarna är inte nödvändigtvis avsikten med besöket i museet, har man barn är kanske museiverkstäder och andra barnrum målet. Den personal besökaren möter är inte dess tjänstemän och föremålsexperter. Går man inte med på en visning möter man sällan museets pedagoger. Alla besökare möter dock entrépersonalen, de flesta möter museets vakter liksom caféets och butikens anställda.

På en övergripande nivå är avhandlingens syfte att belysa hur demokratiska samhällsideal förändrats under 1900-talet med ett statligt museum som empiriskt objekt. Historiska museet är ett ovanligt tydligt statligt och politiskt reglerat museum. Det gäller för hela undersökningsperioden, vilket gör det till ett lämpligt studieobjekt. ${ }^{3}$ Föreskrivna statliga normer är tydliga genom olika regleringsbrev och styrdokument. Här förhandlas och manifesteras kontinuerligt vilka "medborgarna", "besökarna", "gästerna" eller "kunderna" är eller bör vara och vilken museets publika, demokratiska roll är. Kort sagt, vad museet är bra för och vilka det ska tjäna.

Empiriskt undersöker jag hur de publika rummen konkret utformas i relation till skiftande kulturpolitiska mål och museets visioner om det demokratiska, tillgängliga museet. Ett vägande skäl att undersöka barnrum, entré, butik och museets innergård/utomhusrum är att dessa rum uppvisar intressanta spänning- 


\section{Britta ZetTERSTRöM GeSChWind}

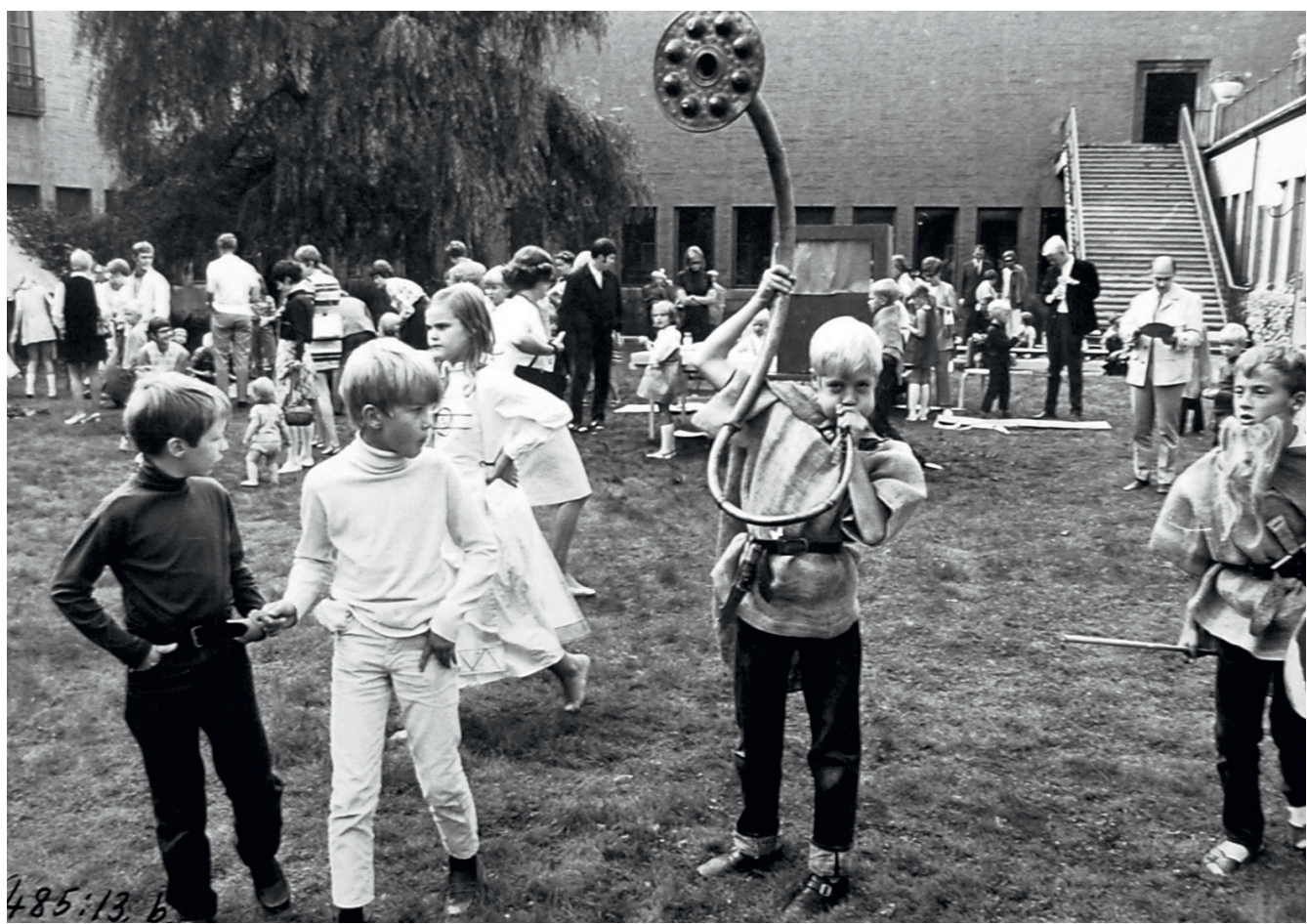

Fig.1. Familjedag 1969 på innergården - museets utomhusrum. Foto: Sören Hallgren, Riksantikvarieämbetet, ATA.

ar i relation till kulturpolitiska mål och museala visioner. De spänningsfält som intresserar mig, i synnerhet mellan kultur och kommers, är tydligare i dessa mindre explicit kulturpolitiskt och musealt reglerade rum, jämfört med utställningarna. ${ }^{4}$ Studiens övergripande frågor är: Hur materialiseras och uttrycks demokratiska ideal? Vilka publiker är det som skapas av de publika rummen? Mer konkret undersöks den rumsliga dispositionen, rummens tillgänglighet och förhandlingar om denna tillgänglighet, hur inredningen sett ut, vilka den anpassats till, vilka som arbetat där och vilka praktiker som försiggått där. När och varför beslutas det till exempel att det ska byggas ett barnrum eller en museibutik? För vilken slags besökare byggs rummen? Hur utformas, omformas och disponeras dessa rum över tid?

Avgränsningen är förbunden med skapandet av museets nya arkitektoniska kropp på Narvavägen och skeenden i huset i krigs- och efterkrigstid fram till nutid. Tyngdpunkten ligger på perioden från museets invigning för allmänheten 1943 fram till och med 2013. Slutåret motiveras av att det kan sägas utgöra slutfasen av ett rumsligt förändringsskede från 2000-talets senare del. Efter 2013 styrdes Sverige dessutom av en ny regering och museet hade fått en ny chef och nya målformuleringar, och 2015 var en ny statlig museiutredning klar. Avgräns- 
ningen är dock inte exakt. Vissa skeenden både före och efter den valda perioden har varit nödvändiga att diskutera.

Avhandlingens ämnesval och problematiseringar utgår mycket konkret ifrån vad Donna Haraway kallar situerad kunskap (1988). Ämnesvalet har sin grund i upplevelser av att arbeta på museet och de positioneringar jag hade som nyutexaminerad arkeolog för nästan tio år sedan. Jag arbetade i funktioner med relationellt låg ställning i museihierarkin: som visstids- och timanställd i butik, entré, bokning, praktisk verkstad och annan barnverksamhet. Det var också praktiker som till övervägande del utfördes och utförs av kvinnor - inte bara på Historiska museet utan mer generellt i Sverige, liksom i Europa och USA. Som högutbildad vit kvinna, visstidsanställd med låg lön passade jag in i ett mönster. Maktrelationerna hade för mig en påtaglig materiell rumslig verklighet, där till exempel "Fornverkstan" för barn låg i källaren och ledningens kontor högst upp i huset. Ett intresse för museets rumsliga dispositioner i relation till frågor om makt och demokrati väcktes. Framför allt kom jag att intressera mig för översättningar mellan å ena sidan officiella målformuleringar och styrande kulturpolitiska direktiv och å andra sidan den konkreta utformningen av de publika rum i museet som en besökare vistas $i$.

Initialt fanns ingen ambition att prioritera genusaspekter i studien, men museets könade karaktär och hur denna materialiseras asymmetriskt i museikroppen, har ständigt blivit synligt för mig. Jag har känt mig underordnad på grund av mitt kön, men inte utifrån min hudfärg, klass eller min kropps rörlighet. Museets könade karaktär har kanske därför framträtt mer för mig än andra maktaspekter. Dock har aspekter av ras, etnicitet, klass och kroppslig funktion framträtt tydligare i andra sammanhang, beroende på vilken tid och vil- ket rum som studerats. Fältarbetena i byggnaden tydliggjorde något jag redan känt som en subjektiv erfarenhet men som jag dittills inte kunnat formulera eller utveckla, nämligen att materiella och rumsliga dispositioner påverkar sociala relationer och vad som kan läras, förstås och erfaras i olika rum. Kulturgeografen Doreen Masseys perspektiv på hur hon förstår rum i termer av makt och genusrelationer har därför varit viktiga för avhandlingen (Massey 1994).

\section{MUSEIRUM OCH MATERIALITET}

Avhandlingen tar sin teoretiska utgångspunkt i aspekterna rum, materialitet och maktrelationer utifrån huvudsakligen tankegångar hos sociologen Bruno Latour och Doreen Massey. Latours sätt att förstå makroaktörer med utgångspunkten att de inte innehar makt utan att den skapas och upprätthålls genom ett nätverk av aktanter och aktörer, materiell omgivning såväl som människor, var en ledstång in i fältarbetet. Latour pekar - i samklang med Michel Foucaults tänkande - på hur makt utövas i alla sociala relationer i en mängd pågående vardagliga (mikro)praktiker (Foucault 1970, Latour 1998:42).

De tidsrumsliga processer som formar museet inbegriper mänskliga kroppar, rum och materiell omgivning. Då museet byggdes blev resultatet av konkurrerande ideal, översatta i många förhandlingar mellan olika aktörer, en kombination av avskalad funktionalism och en mer storslagen, traditionell och nationalistisk stil (Bergström \& Edman 2004:75, 114). Inträdet i det statliga museirummet är ett inträde i ett symboliskt nationellt rum. Museikroppen har en specifik utformning, där tidigare värderingar och synsätt kan dröja sig kvar i materialiserade former (jfr Beckman 1999:21). Att museet färdigställdes i en tid av krig, nationell 
142 samling och folkhemsbygge spelar roll för museibesökarens inträde än idag. Samtidigt är inte museibyggnaden riktigt så fast och solid som arkivens ritningar och husets imponerande fasad kan ge intryck av. Museet är på samma gång både stabilt och rörligt.

Massey ser rum som formade av, och formare av, sociala maktrelationer och beskriver dem som utsträckta sociala relationer, vilka möjliggör att idéer kan verka över tid och avstånd (Massey 1994:2, 2005:2ff., 22). I dessa sociala relationer räknar jag, med inspiration från Latour, inte bara människor utan samspelet mellan människa, rum och materiell omgivning. Masseys syn på rummet har likheter med hur Latour talar om materiella förlängningar, men i Masseys tänkande betonas tydligt hur dessa relationer är ojämlika. Hon beskriver rummet som en ständigt skiftande social maktgeometri. Eftersom sociala relationer alltid är dynamiska och rörliga, är följaktligen också rummet rörligt, menar hon: "Space is not static, nor time spaceless" (1994:263f.). Med stöd i Masseys tänkande ser jag hur funktioner som butik, café, barnverkstad och entré omformas, sväller, krymper, tar utrymme och flyttar runt i huset över tid. I samband med ideologiska skiften kan rum börja skava och rumsliga transformationer initieras. Omdaningar som på ytan verkar triviala kan i praktiken utgöra materialiseringar av förändrade synsätt inom institutionen. Och vad förändras inte, trots intentioner i styrdokument, kritik och utarbetade planer på förändring?

\section{ETT KULTURHISTORISKT ARBETSSÄTT}

Det kulturhistoriska angreppssättet innebär för min studie en pendling mellan mikro och makro, mellan nuet och det förflutna. Det innebär att studera makroaktören genom dess mikropraktiker. Empirin består av observatio- ner, intervjuer, skiftande arkivmaterial i ord och bild, kulturutredningar, politiska och museala styrdokument och massmediala utsagor. Ingen av dessa materialkategorier kan sägas utgöra ett huvudmaterial, de måste ses som sammanflätade. Att kombinera och jämföra källmaterial som belyser ett visst fenomen, men utifrån olika perspektiv och sociala positioner och som tillkommit utifrån skilda syften, kan sägas utmärka en kulturhistorisk och etnologisk metod (Hörnfeldt 2014, Lennartsson 2014). Metoden motiveras av att det är i växelverkan mellan kulturpolitiska mål och vardaglig rumslig, materialiserad praktik mitt intresse ligger. För att få veta något om hur kulturpolitiska mål och ideologiska visioner översätts i rumslig praktik, måste material på olika "skalnivå" studeras relationellt (Lennartsson 2014:15).

Avhandlingen anknyter till en etnologisk tradition som syftar till att synliggöra och problematisera samhälleliga maktstrukturer och de normer som upprätthåller dessa, utifrån ett perspektiv "i marginalen". Ett jämförande historiskt perspektiv kan användas som metod för att skapa djupare förståelse för det nutida sammanhanget. Mitt arbete har i den meningen likheter med Helena Hörnfeldts avhandling Prima barn helt u. a. (2009). I en "analytisk dialog" mellan nu och då skapas en annan kunskap än vad enbart historiska studier eller samtidsstudier kan ge, menar Hörnfeldt (2014:37). Det är också en krävande metod som förutsätter både bredd och djup i materialet. För att kunna uttolka något ur detaljerna i ett förflutet tidsrum, krävs en bredare förståelse av dess tidigare självklarheter.

Med utgångspunkt i Latours nätverk inleddes fältarbetet med observationer och intervjuer och med att följa olika publika verksamheter på museet. Jag lade vikt vid att se relationer och förbindelser mellan människor, rum och före- 
mål. Genom den intervjuteknik som ibland kallas walking ethnography följde jag med anställda i olika positioner genom museet. Tekniken tar fasta på relationen mellan människor och deras omgivning, hur praktiker är kopplade till rum (Anderson 2004:257). Den kan också belysa komplexiteten i hur en och samma miljö kan uppfattas olika. Fältarbetet i museets olika nutida rum gav, tillsammans med egna tidigare upplevelser, den avgränsning och den karta som orienterade mitt sökande in i museets förgångna tidsrum genom såväl intervjuer som arkivets mångskiftande material. Själva husets materialiseringar fick också utgöra ett källmaterial. En detalj som entrédiskens utformning och höjd har exempelvis visat sig vara talande för en skiftande syn på mötet med besökarna i olika tider. Frågan: "Varför just denna rumsliga förändring vid just vid denna tidpunkt?” har varit en analytisk ingång till att undersöka skiften i demokratiska ideal.

Många viktiga rumsliga praktiker finns dock inte representerade i museets arkiv. Därför har själva arkivets organisering och materialiseringar varit viktiga att reflektera över. När anses en viss typ av information värd att bevara? Hur organiseras den sedan i arkivet? Varför har vissa saker sparats medan annat försvunnit eller lämnats oförtecknat? Dels är detta en fråga om reflexivitet, dels är arkivets uppbyggnad en analytisk ledtråd till förståelsen av hur olika verksamheter värderats och till hur museet organiserats över tid. Länge kände jag en frustration över att vissa verksamheter tycktes osynliga eller undanglidande i arkivets organisering. Till exempel har butiken knappt gjort några avtryck alls. Att ta reda på något annat än ekonomiska balanser och inköp, som hur butiken sett ut och var den legat, har varit svårt. Denna frustration byttes snart i insikten om att även bristen på ett visst material kan förstås analytiskt. Hur butiken satt spår i ar- kivet kan delvis förstås utifrån förskjutningar 143 i spänningsförhållandet mellan kommers och kultur i kulturpolitiken och i museet. Att material om barnverksamheten är ojämnt dokumenterat och till stora delar oförtecknat och osorterat säger också något om dess status. Vad som sparas och hur hör samman med politiska, statligt styrda mål, organisationens skiftande sammansättningar, museala hierarkier och praktiker, liksom med arkivets och museets ekonomiska resurser.

\section{EN VANDRING GENOM MUSEETS PUBLIKA KROPP}

Avhandlingen är rumsligt disponerad och inleds med inträdet i museets huvudentré vid tiden för öppnandet 1943. Entrén utgör både en mental och konkret tröskel som ska övervinnas innan museibesöket kan ta sin början. Dess transformationer, både fullföljda och icke genomförda planer, berättar mycket om museets självbild och synen på mötet med besökarna. Fältarbetet i museets förflutna tidsrum uppmärksammade mig exempelvis på hur krig, maskulinitet och nation i huvudentrén tycktes smälta samman. Vissa materialiseringar och maktgeometrier är mer hållbara än andra. Genom åren har olika förslag lagts fram på att göra entrén mer välkomnande, utifrån respektive samtids syn på relationen till besökarna. Trots det har entrén och ytan framför museet ändrats mycket lite. Entréhallen har dock gjorts om i några tydliga skeden, senast under mitt fältarbete då den har smält samman med museibutiken, vilken behandlas i ett eget kapitel.

Butiken är ofta det sista rum en besökare upplever, men den kan också vara det första. Idag är allt fler museibutiker förlagda till museers entréer. De utrymmen som upplåtits till museibutiker, caféer och restauranger har starkt utökats under senare decennier (Hoo- 
144 per-Greenhill 1992:202ff., Conn 2010:24f.) och man kan ofta besöka butiken och restaurangen utan att betala entré till museet. Det är nästan otänkbart att ett museum inte skulle ha en butik. Museibutiker har upphöjts till att vara viktiga delar av museets varumärke, eller genrerepertoar, ett begrepp hämtat från kulturhistorikern Anne Eriksen (Eriksen 2009:15ff., Kent 2010:68). Jag undersöker därför hur butiken tagit plats i museibyggnaden. När fanns det för första gången en museibutik? Hur förhåller sig framväxten av butiken till de kulturpolitiska mål och styrdokument museet har att hålla sig till? Hur har synen på butiken skiftat? Vilka har arbetat här? Hur kan butiken förstås som ett publikt rum?

Museibutiken kan ses som ett miniatyrmuseum som speglar det stora, med skillnaden att föremålen här kan ägas och beröras (jfr Gustafsson 2008:89). I både butik och utställningar väljs noga ut vad som ska exponeras och hur, här skapas taxonomier och informationsskyltar om föremålen. Både utställningar och butiker bjuder in allmänheten/besökarna/konsumenterna i rum där dessa förväntas bete sig på särskilda sätt och skapa en affektiv relation till materiella ting (jfr Macdonald 2012). Butiken kan dock ses som ett mer tillåtande, informellt rum. Dess multisensoriska egenskaper ger särskilda möjligheter att förmedla närhet till andra tider, både pedagogiska och inkluderande. Historien kan här till skillnad från i utställningarna, luktas, smakas och kännas på och till och med ägas.

En allmän uppfattning är att museibutiker representerar motpolen till masskonsumtion. Kultur och kommers har ofta fungerat som binära termer, vilka ömsesidigt förstärkt varandras mening. Spänningsförhållandet mellan kultur och kommers och hur det förändrats över tid är tydligare i museibutiken än i andra rum. I synen på museets demokratiska, inklu- derande roller har butiken osynliggjorts i relation till de "autentiska" och meningsskapande utställningsrummen.

Idag är det närmast självklart att varje museum har någon form av barnverksamhet i ett särskilt anpassat utrymme. Ofta är kopplingen barn-museum-lärande så stark att barn- och skolverksamhet kommit att bli ett fundament för museernas politiska legitimitet. Inom kulturpolitiken är barn och unga ett högt prioriterat område. ${ }^{6}$ Barnverksamhetens betydelse behöver inte motiveras mer än i generella ordalag. ${ }^{7}$ Den har med ett Latourskt språkbruk "svartlådats". Barn har dock inte alltid haft en självklar plats i museet, inte ens när de har tilldelats särskilda utrymmen. Ett tankeväckande resultat är att trots att allt fler rum och praktiker utformats för barn, och att kulturpolitiken betonar barns demokratiska rättighet till kultur, finns det en stark kontinuitet i att alla museets barnrum från 1945 till idag har beskrivits som tillfälliga och provisoriska lösningar i väntan på permanenta lokaler.

När Historiska museet öppnade i Nationalmuseum år 1866 var den självklara målgruppen vuxna. Från 1920-talet blev visningarna för skolbarn allt fler. Åren efter invigningen av den nya museibyggnaden ökade antalet visningar och program för skolklasser och skollovsungdom kraftigt. Under 1940-talet inreddes museets första provisoriska Lektionsrum för skolbarn. 1963 invigdes Barnens rum. 1976 installerades Lekverkstaden. Hur barn fått ta plats i museikroppen har varit intimt förbundet med vad man tänkt sig att barnen ska lära sig, på vilket sätt och varför. Implicit handlar det om vilket slags medborgare barnen ska fostras till. Därmed är museets förhållande till barn en indikation på institutionens samhälleliga roll. Rummen är utformade efter barnens förväntade, eller önskade, beteende. Hur har rummen sett ut och var har de legat? För vilka 
praktiker har de utformats? I relation till det diskuteras barnverksamhetens organisation samt vilka som arbetat med barn och unga, vad de har haft för titlar och vad som varit målen för arbetet. Detta ställs i relation till en skiftande kulturpolitik och pedagogisk utveckling. Samtidigt som den pedagogiska verksamheten är bland museernas mest synliga verksamhet i offentligheten, i statliga dokument och i museologisk facklitteratur - är den anmärkningsvärt lite dokumenterad inom museerna (Ljung 2009). Detta gäller även för Historiska museet.

I avhandlingens sista empiriska kapitel besöks den grönskande innergården, vilket jag betraktar som ett av många möjliga "momentana rum". Med detta menar jag museirum där museets budskap har kunnat förstärkas, eller inverteras temporärt - det vill säga museirum som temporärt omklätts till något annat, till exempel marknadsplats, konferens- eller festlokal. Innergården är ett utomhusrum omgärdat av museets utställningssalar och kan beskrivas som liminalt. Det ligger både mitt inuti museikroppen och utanför den. Det har gett den särskilda möjligheter i relation till besökarna, i synnerhet till barn.

I avhandlingens avslutande kapitel med arbetsnamnet "Rörliga rum och rörelser genom rum", kommer avhandlingens slutsatser att summeras med avseende på förändring och kontinuitet. Hur har museet varit publikt och hur har synen på det publika/offentliga uppdraget förändrats över tid? Här problematiseras även avhandlingens rumsliga indelning. Museet har visserligen olika slags publika rum som rymmer olika funktioner: utställningsrum, butik, entré, café och barnrum. Men rummens och praktikernas gränser är flytande. Museet är inte bara sina rum, utan även summan av rummen och relationen mellan olika rum.
Noter

1. Clifford 1997. Bhabhas utveckling av begreppet third space (Bhabha 1994) har fångats upp i en rad museistudier och i museernas begreppsflora under senare år (se t.ex. Sandell 2007, Bodo 2009, Schorch 2013). I Sverige har det diskuterats som "tredje rummet". Dessa metaforer behandlas i en artikel av Vaike Fors (2012).

2. Det senare spänningsparet närmast jämförbart med idealtyperna folkhögskolan och teatern i Hillströms och Beckmans modell.

3. Museets betydelse i den nationella kulturpolitiken är tydligt i den nya museiutredningen $N y$ museipolitik (SOU 2015:89).

4. Initialt var ambitionen att inkludera museets restaurang. Anledningen till att denna tar liten plats i avhandlingen är att den alltid har drivits av externa aktörer och därför inte har omfattats av museets målformuleringar i någon större utsträckning. Den har även i mycket blygsam omfattning avsatt material i arkivet.

5. I synnerhet ansluter studien till etnologisk forskning som intresserar sig för frågor om makt utifrån en samhällsinstitution som fysiskt objekt, t.ex. sinnessjukhus, andra vårdinstitutioner och fängelser (se t.ex. Svensson 1993, Öhlander 1996, Jönsson 1998, Hörnfeldt 2009).

6. Tid för kultur, prop. 2009/10:3, http://www. regeringen.se

7. Även andra historieförmedlande aktörer, på skalan mellan institutionella museer och kommersiella nöjesparker, legitimerar sin nytta och relevans med barnverksamhet, vilket bekräftas genom statliga och kommunala medel. I styrdokument från regeringen 2011 fick 26 statliga kulturinstitutioner uppdrag att utforma strategier för sin barn- och ungdomsverksamhet för 2012-2014. 


\section{LITTERATUR}

Anderson, Jon 2004. "Talking whilst walking. A geographical archaeology of knowledge." Area 36:3, 254-261.

Bergström, Anders \& Victor Edman 2004. Folkhemmets museum. Byggnader och rum för kulturhistoriska samlingar. Stockholm: Byggförlaget.

Beckman, Jenny 1999. Naturens palats. Nybyggnad, vetenskap och utställning vid Naturhistoriska riksmuseet 1866-1925. Stockholm: Atlantis.

Bhabha, Homi K. 1994. The Location of Culture. London: Routledge.

Bodo, Simona 2009. "The challenge of creating 'third spaces. Guidelines for MAP for ID pilot projects." I Simona Bodo, Kirsten Gibbs \& Margherita Sani (red.). Museums as Places for Intercultural Dialogue. Selected Practices from Europe. MAP for ID Group.

Conn, Steven 2010. Do Museums Still Need Objects? Philadelphia: University of Pennsylvania Press.

Fors, Vaike 2012. "The empty meeting place. Museum metaphors and their implications for learning." Designs for Learning 5:1-2, 130-145.

Foucault, Michel 1970/2002. The Order of Things. An Archaeology of the Human Sciences. London: Routledge.

Gustafsson Reinius, Lotten 2005. Förfärliga och begärliga föremål. Om tingens roller på Stockholmsutställningen 1897 och Etnografiska missionsutställningen 1907. Stockholm: Etnografiska museet.

Haraway, Donna 1988. "Situated knowledges. The science question in feminism and the privilege of partial perspective." Feminist Studies 14:3, 575-599.

Hillström, Magdalena 2005. "Arvtagarna. Minnen och museipolitik vid Nordiska museet och Skansen kring 1902." I Magdalena Hillström \& Peter Aronsson (red.) Kulturarvens dynamik. Det institutionaliserade kulturarvets förändringar. Linköping: Linköpings universitet.
Hillström, Magdalena \& Svante Beckman 2001.

"Museiväsendets väsen." Tvärsnitt 23:4, 32-43.

Hooper-Greenhill, Eilean 1992. Museums and the Shaping of Knowledge. London: Routledge.

Hörnfeldt, Helena 2009. Prima barn, helt u.a. Normalisering och utvecklingstänkande i svensk barnhälsovård 1923-2007. Göteborg: Makadam.

Hörnfeldt, Helena 2014. "Etnologiska möjligheter. Om rörlighet mellan historia och samtid." Kulturella Perspektiv 3, 30-39.

Jönsson, Lars-Eric 1998. Det terapeutiska rummet. Rum och kropp i svensk sinnessjukvård 1850-1970. Stockholm: Carlssons.

Kent, Tony 2010. "The role of the museum shop in extending the visitor experience." International Journal of Nonprofit and Voluntary Sector Marketing 15:1, 67-77.

Latour, Bruno 1998. Artefaktens återkomst. Ett möte mellan organisationsteori och tingens sociologi. Stockholm: Nerenius \& Santérus.

Lennartsson, Rebecka 2014. "Arkivetnografi, eller reflektioner över en tappad biljett." Kulturella Perspektiv 3, 8-18.

Ljung, Berit 2009. Museipedagogik och erfarande. Stockholm: Stockholms universitet.

Macdonald, Sharon 2012. "The shop. Multiple economies of things in museums." I Friedrich von Bose, Kerstin Poehls, Franka Schneider \& Annett Schulze (red.) MuseumX. Zur Neuvermessung eines mehrdimensionalen Raumes. Berlin: Panama Verlag.

Massey, Doreen 1994. Space, Place, and Gender. Minneapolis: University of Minnesota Press.

Massey, Doreen 2001. "Talking of space-time." Transactions of the Institute of British Geographers, New Series 26:2, 257-261.

Sandell, Richard 2007. Museums, Prejudice and the Reframing of Difference, London: Routledge.

Schorch, Philipp 2013. "Contact zones, third spaces, and the act of interpretation." Museum and Society 11:1, 68-81.

Svensson, Birgitta 1993. Bortom all ära och redlighet. 
Publika museirum

Tattarnas spel med rättvisan. Stockholm: Nordiska museet.

Öhlander, Magnus 1996. Skör verklighet. En etnologisk studie av demensvård i gruppboende. Stockholm: Stockholms universitet.

\section{ELEKTRONISKA KÄLLOR}

Ny museipolitik, SOU 2015:89

http://www.regeringen.se/rattsdokument/statensoffentliga-utredningar/2015/10/sou-201589

Tid för kultur, prop. 2009/10:3

http://www.regeringen.se/rattsdokument/

proposition/2009/09/prop.-2009103
Britta Zetterström Geschwind, doktorand Etnologiska avdelningen/Forskarskolan för kulturhistoriska studier (Fokult) britta.geschwind@etnologi.su.se.

Institutionen för etnologi, religionshistoria och genusvetenskap

Stockholms universitet

SE-106 91 Stockholm, Sverige 